Meta

Journal des traducteurs

Translators' Journal

\title{
Remapping Translation Studies: Towards a Translation Studies Ontology
}

\section{Sonia Vandepitte}

Volume 53, numéro 3, septembre 2008

URI : https://id.erudit.org/iderudit/019240ar

DOI : https://doi.org/10.7202/019240ar

Aller au sommaire du numéro

Éditeur(s)

Les Presses de l'Université de Montréal

ISSN

0026-0452 (imprimé)

1492-1421 (numérique)

Découvrir la revue

Citer cet article

Vandepitte, S. (2008). Remapping Translation Studies: Towards a Translation Studies Ontology. Meta, 53(3), 569-588. https://doi.org/10.7202/019240ar
Résumé de l'article

Cet article perçoit la traduction comme une activité humaine intentionnelle et présente un thésaurus des études de la traductologie. Il contient tous les concepts de la multitude des différents domaines de la traductologie dans Baker (1998a), la « Bibliography of Translation Studies » (1998-), Williams and Chesterman (2002) et la « EST-Directory 2003 ». Tous sont réunis dans une seule carte qui révise la carte de Holmes (1972). Des avantages pratiques additionels pour la traductologie sont mis en relief. 


\title{
Remapping Translation Studies: Towards a Translation Studies Ontology'
}

\author{
SONIA VANDEPITTE \\ University College of Ghent, Gent, Belgium \\ sonia.vandepitte@hogent.be
}

\begin{abstract}
RÉSUMÉ
Cet article perçoit la traduction comme une activité humaine intentionnelle et présente un thésaurus des études de la traductologie. Il contient tous les concepts de la multitude des différents domaines de la traductologie dans Baker (1998a), la «Bibliography of Translation Studies» (1998-), Williams and Chesterman (2002) et la «EST-Directory 2003». Tous sont réunis dans une seule carte qui révise la carte de Holmes (1972). Des avantages pratiques additionels pour la traductologie sont mis en relief.
\end{abstract}

\begin{abstract}
Building on a common view of translation as a human intentional activity, this article presents a translation studies thesaurus in which all concepts from the multitude of different translation studies areas listed in Baker (1998a), the "Bibliography of Translation Studies" (1998-), Williams and Chesterman (2002) and the "EST-Directory 2003" are brought together on a single map that revises Holmes's map (1972). Additional practical advantages for the study of translation studies are pointed out.
\end{abstract}

MOTS-CLÉS/KEYWORDS

translation studies, Holmes's map, thesaurus, meta study

\section{Introduction}

The proliferation of translation studies from the second half of the twentieth century until now has produced a multitude of approaches, models, concepts and terms. Translation studies has become a labyrinth of ideas and findings in which it is hard to find one's way and about which explicit consensus has been formulated fairly rarely. However, within the framework of the Bologna-agreement, European Union institutions are now obliged to work towards transparency and mutual recognition of degrees, a fact that stimulates translation studies to reflect on its own status. Recent surveys of the field's contents can be found in Baker (1998a), the "Bibliography of Translation Studies" (1998-), Williams and Chesterman (2002) and the "ESTDirectory 2003." These overviews are very incongruent, however: the few subdivisions of types of translation studies areas that are marked clearly differ from one another, and, taken together, these contributions result in a collection of fairly long lists of translation studies approaches that lack a consistent basis. Consequently, one still turns to Holmes's map of translation studies to build some coherence into the complex collection of theories and findings about translation. The present article explains why Holmes's map is inadequate for this purpose, outlines its shortcomings and develops an alternative. 


\section{Translation as a state of affairs within a causal sequence}

There is no question in translation studies that translation is an act of human communication. Even more generally speaking, translation is an intentional human activity that is carried out by an agent. Whether one distinguishes translational types like Jakobson (1959), follows Hermans's scheme of the communicative process of translation (1998: 155), applies Delisle et al.'s “Steps of a Translation" (1999) or even Bloemen and Segers's Dutch translation of those steps (2003), with its different order and nomenclature (2003), under all views, the translation activity is applied by a human agent to an object, the source text or source discourse, and the result is a new product, i.e., the target text or target discourse. This activity takes place in certain circumstances: with certain means in a certain place at a certain time. As we will see, it is important to recognize that this activity constitutes one distinct state of affairs $^{2}$ on its own (Figure 1).

FIGURE 1

Translation as a state of affairs

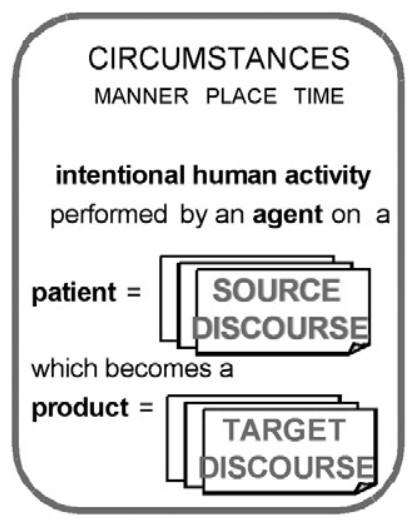

Indeed, some of the circumstances preceding the activity of translation may be seen as the causal factors of translation. Like any other activity, translation is the result of certain willed circumstances. In addition, it also has its own consequences, so that it can be seen as the middle stage in a causal sequence (Chesterman 2000; Figure 2). Since an important characteristic of translation is the fact that the source and target discourses usually belong to different cultures, the translation activity is also a intercultural process. 
FIGURE 2

Translation as a state of affairs in a causal sequence

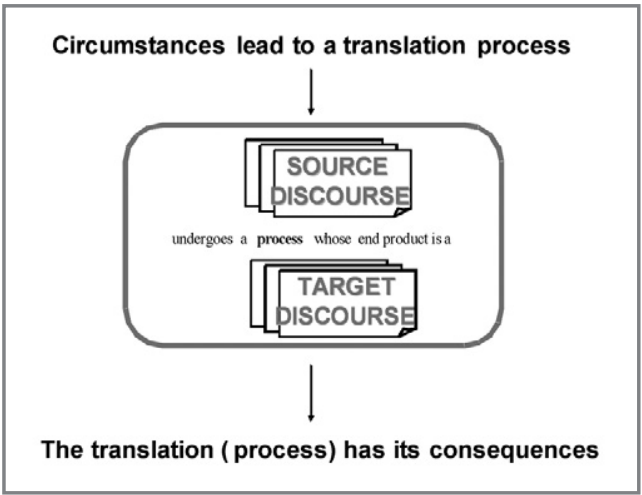

\section{Holmes's map of translation studies}

Presenting a survey of what happens within translation studies is a complicated task. Holmes made the first attempt in 1972. This map (Figure 3) is widely accepted (Baker 1998b: 277b) and consists first of a division into pure and applied translation studies. Pure translation studies is subdivided into theoretical and descriptive translation studies, and applied translation studies is subdivided into translation training, translation aids and translation criticism. Descriptive translation studies is further subdivided into process-oriented, product-oriented and function-oriented studies. There is a further subdivision ${ }^{3}$ but I would like to return to the descriptive translation studies because it is these studies, according to Toury in his volume on descriptive translation studies (1995; cf. also Baker 1998b: 279), that are so closely interrelated that they do not need to be separated. Toury also points out another interrelationship in the map, i.e., that between the pure studies and the applied ones and says that the former should influence the applied extensions and not vice versa.

FIGURE 3

Holmes's map

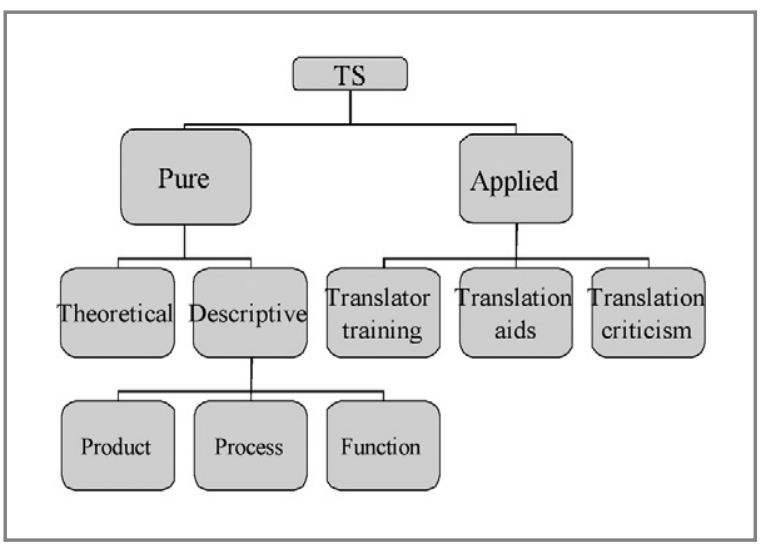


However, Holmes's map is marred by conceptual and heuristic inconsistencies that become apparent when his terms are submitted to the norms developed in the discipline of terminology. In terminology (Aitchison et al. 2000), a field closely related to translation studies, terms, Lead Terms, may conceptually cover different types of Narrow Terms. These different classes are indicated by means of 'type by ...' followed by a particular criterion. In the following extract from a mini-thesaurus, two criteria for subdividing among human beings are age and gender:

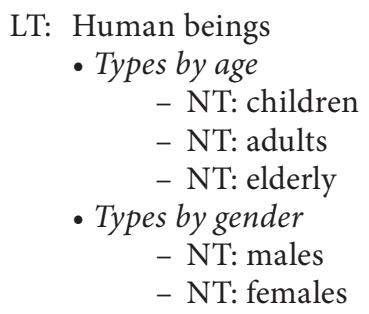

If this thesaurus needs to include another characteristic along which all human beings can be classified, for instance, the language they speak, it will not be entered into one of the subclassifications above, but as a third criterion, viz. 'type by language' of 'human beings':

LT: Human beings

- Types by age

- NT: children

- NT: adults

- NT: elderly

- Types by gender

- NT: males

- NT: females

- Types by language

- NT: Afro-Asiatic

- NT: Sino-Tibetan

- NT: Indo-European

- NT: Iroquoian

- NT: Arawakan

- NT: Austronesian

- ...

It is precisely this consistent application of criteria which is missing in Holmes's map. The first distinction in his map, between pure translation studies branches and the applied ones, is based on what one could call the purpose of the study: pure branches aim at knowledge, whereas applied sciences also aim at a particular change. Looking at the subdivision of the pure studies no longer reveals the criterion of purpose, but rather that of method. This criterion is, however, not used for the subdivision among the applied studies: they are further subdivided according to the subject they focus on (Figure 4). This is the point at which the consistency is interrupted: both criteria of 'method' and 'subject' are not exclusively reserved for the subclassification into which Holmes has put them. Indeed, applied studies, too, rely on theoretical frameworks: all topics within translation studies can be described objectively by means of a theoretical framework. And applied translation studies are also based on empirical findings, a fact which Toury tries to solve by pointing out the interrelationships. In 
Holmes's map, however, theoretical and descriptive translation studies are restricted to the domain of pure studies only. Conversely, pure studies may also cover topics that are the alleged province of applied translation studies. Clearly, as Toury pointed out, too, translation theory and applied translation studies are not separate entities.

FIGURE 4

\section{Criteria in Holmes's map}

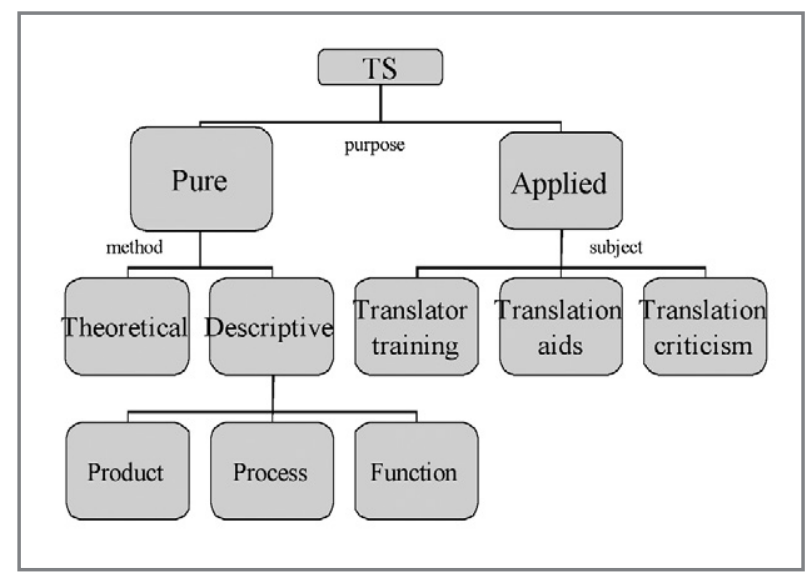

This criterion of inconsistency leads to further problems with Holmes's map. Toury, for instance, rightly notes that Holmes "neglected to duplicate his division of the theoretical branch into 'partial theories' in descriptive translation studies" (1995: 11 n.5). But there are more troublesome points. One is the separation between translation aids (among the applied sciences) and the translation process (among the pure ones). Obviously, translation tools, which Holmes would classify among translation aids, are used to facilitate the translation process and should form an integral part of that process.

Another problem is the presentation of product, process and function as colleague terms. According to the definition, product and process are both definitional entities of the translation event. Function, however, refers to one of the important results of the translation: it is a state of affairs in itself. Even though its "envisaging" may be interacting with the translation process, it is temporally quite distinct from the other two.

\section{Remapping translation studies}

The new map presents its categories according to a rigid set of criteria, placing all kinds of translation studies into a coherent visualized survey. The map elements are all translation studies areas taken from the lists drawn up by Holmes (1972), Baker (1998a), the "Bibliography of Translation Studies" (1998-), Williams and Chesterman (2002) and the "EST-Directory 2003." Starting-point for this new map is the notion of scientific or academic discipline. Since any academic discipline - whether it be literary studies, Asian, Buddhist, medieval, gender or strategic studies, sociology, psychology, medicine, or physics - has its own purposes, its own methods, and its 
own object (which can be split up into various parts), the map distinguishes the following three typologies of translation studies:

1. translation studies typology based on the purpose aimed at, in other words the research question that is formulated;

2. translation studies typology based on the method employed; and

3. translation studies typology based on the subject covered.

These typologies are not fixed regiments with their fixed number of soldiers. Instead, they provide labels for distinguishing the specific character of a particular study within the various typological contexts that each study participates in. Each study can - and in a field bibliography needs to - be characterized by means of a label from each of the three different typologies. Needless to say, an investigation may have more than one purpose, use different methods, and cover different areas of the translation studies field.

\subsection{Translation studies typology based on the purpose aimed at}

Research involves at least three different stages: description, explanation and prediction. Descriptive translation studies or DTS (Toury 1995) can therefore be distinguished from explanatory translation studies (e.g., Gutt 2000) and from predictive translation studies (e.g., Olohan 1998). Note that Toury (1995) actually includes the three types within his 'descriptive translation studies.' And although the best theoretical studies indeed include these three types, those focussing on just one research stage may also be worthwhile and contribute to a translation theory (Holmes's 'pure translation studies' 1972, “Bibliography of Translation Studies” 1998-, Venuti 2004) or translatology in its broad sense (e.g., Uwajeh 2002).

The three different knowledge-oriented types of studies differ from those studies that aim at something beyond pure knowledge, i.e., some or other outcome or change (see also Figure 5). These are usually normative studies: with the new knowledge achieved, they also aim at particular norms, standards, or practical outcomes. Most of those studies (but not all) are found among Holmes's 'applied translation studies.' They include many models within translation teaching that aim at students performing translation in a certain way: Lederer's interpretive model (1980 and 1981) or teaching models proclaiming particular translation ethics are good examples. Other less purely knowledge-oriented studies include cultural translation (with its performative theory) or translation ethics (studies that discuss and prescribe a particular type of ethics, starting from specific but not always specified cultural and ideological norms). ${ }^{4}$

FIGURE 5

Categorization according to purpose

\begin{tabular}{|ll|}
\hline Knowledge & Knowledge + change \\
- Descriptive TS & - SOME T teaching, T aids \\
- Explanatory TS & \\
- Predictive TS & $\begin{array}{l}\text { - SOME T ethics, } \\
\text { T criticism, c ultural T } \\
\end{array}$ \\
& (performative theory) \\
\hline
\end{tabular}




\subsection{Translation studies typology based on the method employed}

To a large extent, each investigation method is determined by the purpose and the subject. The map distinguishes four main types: deductive translation studies, experimental approaches, speculative ones and inductive translation studies (incl. corpus-based studies, e.g., Olohan 2004) with its qualitative, quantitative and hermeneutic approaches.

Some fields of translation study also apply methods typically related to their field: linguistic, neurolinguistic, cognitive, psycholinguistic, behavioural, communicative / functional, semiotic, sociological approaches in interpreting, etc. Figure 6 illustrates the diversity of methodological approaches:

FIGURE 6

Categorization according to method

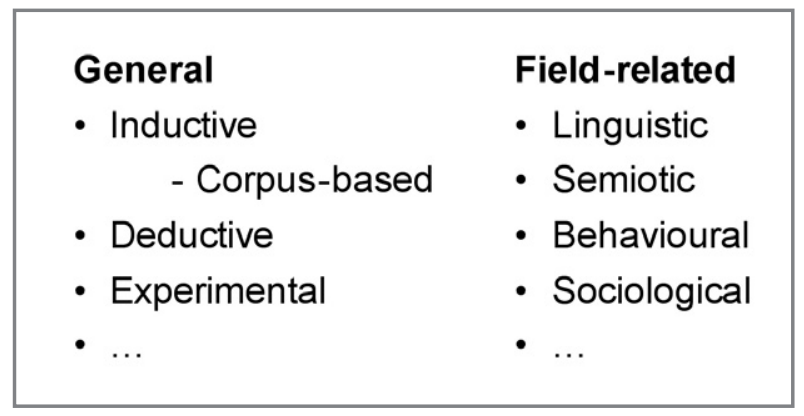

\subsection{Translation studies typology based on the subject covered}

It is the third type of typology that is most commonly used in science: it groups studies according to the subject under investigation. This may vary from a very specific aspect to a broader subject and even a whole field or domain. For practical purposes, the investigations studying a single item of the translation process will be referred to as the single-subject studies, the studies covering more than one single focus as multi-focus studies, ${ }^{5}$ and those that cover all foci will be called 'umbrella' studies.

\section{Single-subject studies: four translation studies foci}

In building a subject-based typology or ontology of translation studies, it is useful to start from the translation situation and to distinguish four translation foci. Two are derived from the definition of translation (discourse and process) and two come from the causal view that is taken (cause and result).

In the definition of translation two types of foci can be distinguished. On the one hand, there is the translation process itself with all its component processes: all the activities and change-inducing events involved in the translation process (5.1). On the other hand, the process is applied to some discourse, viz. the source text / discourse, and the outcome is a second piece of discourse, viz. the target text / discourse or product (5.2). 
Both the translation process and the discourse to which it is applied are to be found in a particular situation: the translation process is one link in a causal chain, with some circumstances, i.e., the causal factors, leading to the translation process (5.3), and with some circumstances, i.e., the results, derived from the translation process (5.4). Cause and result are, indeed, the other two translation foci. For a survey, see Figure 7 below:

Figure 7

Categorization according to subject

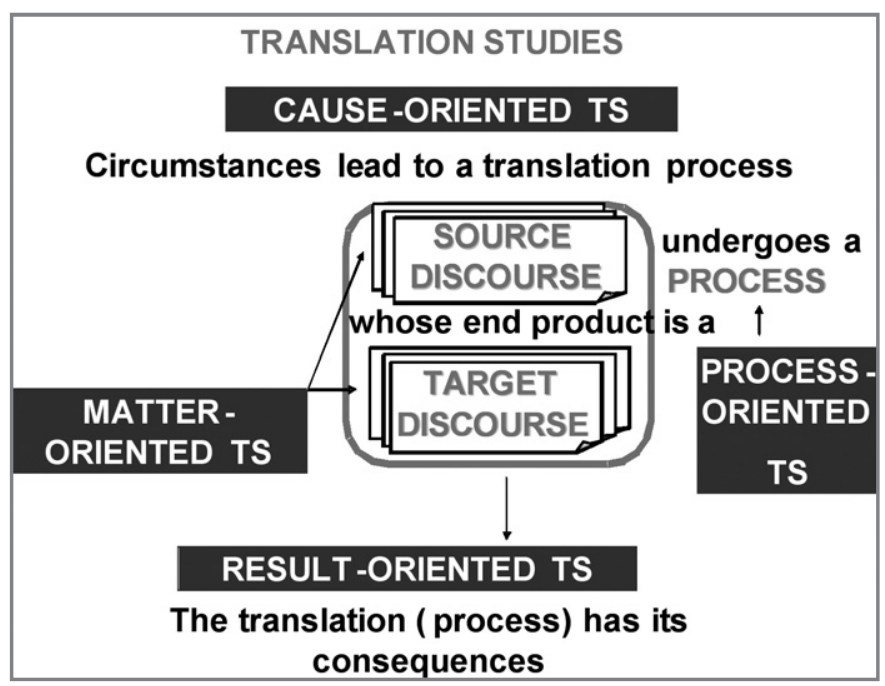

\subsection{Process-oriented studies}

The process-oriented translation studies collate with Holmes's process-oriented studies: they focus on the process of translating itself. Research questions here deal with various aspects of the translation process: individuals' translation competence and its development, and the actual performance of the translators within their professional situation.

\section{a. Translation competence research}

In translation competence research, translators are seen as individuals going through the translation process and taking many decisions, e.g., in translation commentaries (considering either introspective or retrospective aspects of the translation process). Decisions are taken consciously or unconsciously: they may involve translation strategies $^{6}$ (aiming at equivalence, explicitation, free translation vs. literal translation ${ }^{7}$ vs. sense-for-sense translation (Jerome AD 395), rank-bound vs. unbounded translation (Catford 1965), imitation, metaphrase, paraphrase, pseudotranslation, adaptation, domestication vs. foreignization, etc.) or linguistic translation techniques (leading to linguistic translation shifts). Whether the translation process takes place with or without technological aids, studies of translation and technology also belong to this type of translation study, i.e., studies of machine(-aided) translation, (evalu- 
ation of) translation software, localizing software, the effects of technology and website translation (Williams and Chesterman 2002: 14-5). Very often, translation decisions are influenced by (un)conscious ideological assumptions: ideology and translation (e.g., Bassnett and Lefevere 1990). The directionality of the translation, too, may influence the translation process. Other issues related to translation competence are translatability and the functioning of the translation unit as the input of the translation process, game theory (e.g., Levý 1967) and obtaining Walter Benjamin's 'pure language' (Bush 1998: 194-196).

\section{b. Translation competence development research}

How to improve students' translation competence is a very frequent subject in translation studies: translation teaching / training / didactics forms a fruitful field of study (for instance, the Paris school teaching model of interpretive translation). The area includes issues such as translation curriculum design, programme implementation, translation assessment or evaluation, translator training institutions and the place of technology in translation training (Williams and Chesterman 2002: 16).

\section{c. Translation profession research}

The translation profession as such generates scholarly attention too, regarding issues such as the workplace (incl. societies like AIIC and FIT), professional development and other professional issues, ethics (sometimes made explicit in codes of practice, cf. Williams and Chesterman 2002: 19) and quality assessment of professional translations, i.e., translation quality.

\subsection{Discourse-oriented studies}

The discourse-oriented studies cover Holmes's product-oriented studies and can moreover be seen to correspond to Chesterman's source-target supermeme (2000a). They should be subdivided into two main categories: either they investigate both the source and target texts and are therefore of a comparative nature (Williams and Chesterman 2002: 6-7) or they look at texts in general and belong to the collection of what has often been referred to as the 'auxiliary studies' in translation studies.

Among the comparative discourse-oriented translation studies, we can count studies comparing source with target texts - whether or not corpus-based. Examples are source-oriented translation quality assessment studies (Williams and Chesterman 2002: 8), and studies that investigate language-related contrasts relying on methods from contrastive linguistics, contrastive pragmalinguistics, contrastive pragmatics, or contrastive discourse analysis (one research question could be: what happens to the multilingualism in a source text?) Other investigations rather focus on the similarities in different discourses (and rely on comparative linguistics). Discourseoriented studies also include contrastive area studies (with research questions like "what are the cultural, political, economic institutions in one area and what are their equivalents in another area?") and analytical philosophy, which claims that translation is indeterminate (Quine) because it is impossible for source and target texts to have the same meaning.

Further, some comparative discourse-oriented studies compare translations with a corpus of comparable, non-translated texts as in studies of translation universals 
and target-language oriented translation quality assessment (Williams and Chesterman 2002: 8).

Among the non-comparative discourse-oriented translation studies belong discussions of translation anthologies (Essman 1992) and of script in translation. Most studies, however, look at features of texts within just one language or at those features that are seen as universal. They include linguistics (semantics, syntax, phonology), text linguistics, textology, translation of humour / wordplay / metaphor, critical linguistics, applied linguistics, stylistics, terminology (incl. term banks, applications, standardization), terminography, lexicology, lexicography, terminotics, thesaurus / ontology building, semiotics, or discourse studies, incl. dialogue language and technical writing. Since interpretation is essential to the translation process, the map introduces automatic content retrieval as a new area.

\subsection{Cause-oriented studies}

Studies focussing on the cause of the translation process usually investigate translation politics and translation publishing strategies. Discussions of translation and ethics or socio-political aspects belong to this type of translation studies. Researchers also consider cultural and ideological factors that have influenced translation (power, colonialism, cultural identity) and zoom in on notions such as the ethnocentric violence of translation (Venuti 1995) and the cultural turn in translation studies (Bassnett and Lefevere 1990).

\subsection{Result-oriented studies}

Result-oriented studies primarily concentrate on the consequences resulting from a certain translation (activity). This may be its effectiveness, the topic of effect-oriented translation quality assessment studies (Williams and Chesterman 2002: 8-9), or how a certain translation (activity) functions either in language teaching or at a more general level (Holz-Mänttäri's action theory, Vermeer's skopos theory, Even-Zohar's polysystem theory) or how it contributes to the construction of an ethics, or a literary canon, or a cultural identity (translation and cultural identity, the translator's invisibility Venuti 1995).

\section{Multi-focus and 'umbrella' studies}

These single-subject studies are complemented by studies whose research questions involve more than one subject focus. The areas of discourse and process are often considered together, as is evident in examinations of the direction of translation (incl. bi-directionality), hermeneutic motion, ${ }^{8}$ and in translation commentaries relating the target text to the translation process. Both discourse and result play a major role in translation reviewing and criticism as well as in other quality assessment studies. Cause and result are focussed in studies of translational norms ${ }^{9}$ (e.g., Toury 1995: 53). You will also find them in investigations discussing translation ethics and Otherness or the image of the Other (cf. Chesterman's supermeme of untranslatability, 2000a). Cause, discourse and result are subjects in the poetics of translation, which compares the "poetics of a source text in its own literary system" (Gentzler 1998: 167) with that of the translation in the target literary system. 
Sometimes, studies even cover all four foci, and may thus be classified as 'umbrella' studies, which relate the four subjects to one particular aspect or perspective. Register ${ }^{10}$ translation studies, for instance, focus on a particular type of register: religious translation (incl. a.o. Bible, Torah, and Qur'ān translation), the translation of political texts and of texts within LSP (Language for Specific Purposes), which covers business, advertising, tourism, academic, legal and technical texts. Literary translation studies also deals with all aspects of translation: Shakespeare translation is a profoundly developed topic, but scholars investigate all genres (prose, poetry and drama [theatre and opera]) both for adults and children, relying on (comparative) literature studies.

Translation criticism, ${ }^{11}$ too, belongs to the umbrella studies: not only may its prescriptive approach be related to the translation-initiating circumstances, or to the function of the translation in the target audience, it is also related to how the translation should be processed or which texts are (in)appropriate for translation.

The study of auto-translation is another umbrella study. Focussing on self-translations, it comments on those translation situations in which the two most central actors, i.e., the source text writer and the translator, are represented by the same person or institution.

Similarly, interpreting studies should be classified among the umbrella studies: they deal with those specific translation situations where either source text and / or target text is spoken or where the translation appears immediately: conference interpreting, community interpreting, court interpreting, chuchotage, liaison interpreting, sight translation, interpreting for the blind, multimedia translation (incl. voice to written text translations [subtitling, surtitling incl. technological aids] and revoicing [incl. narrator, free commentary, voiceover and lip-sync dubbing], etc.). A special instance is that of sign language interpreting studies which focuses on those interpreting performances in which the discourse consists of (manual) gestures. In all interpreting situations, studies may be both discourse-, process-, cause- and result-oriented.

More traditional perspectives for translation study are space and time, embracing 'history of translation' studies or investigations of 'translation in' a particular geographic area (cf. all translation traditions determined by place / language in Baker 1998: 295ff). These studies may in principle cover the same wide collection of subjects that translation studies as a whole does. Or a study may even be written from both a temporal and a spatial perspective ('(post-)colonial translation'). Another perspective is that of gender, where one investigates the gender of authors translated or of translators (e.g., Simon 1996 and von Flotow 1997). Finally, scholars have also investigated the ideological, socio-political or pragmatic aspects of translation in general.

\section{Towards a Translation Studies Ontology}

I have presented a thesaurus of translation studies (translation studies) which is seen as part of intercultural communication studies, and presumes its own meta-level, i.e., its own bibliography and the study of itself, incl. its research methodology $y^{12}$ and its research training.

The map further contains categorizations of translation studies that are research purpose-based, research method-based and research subject-based. Figure 8 presents a brief survey of the types of translation studies proposed: 
FIGURE 8

Translation studies survey

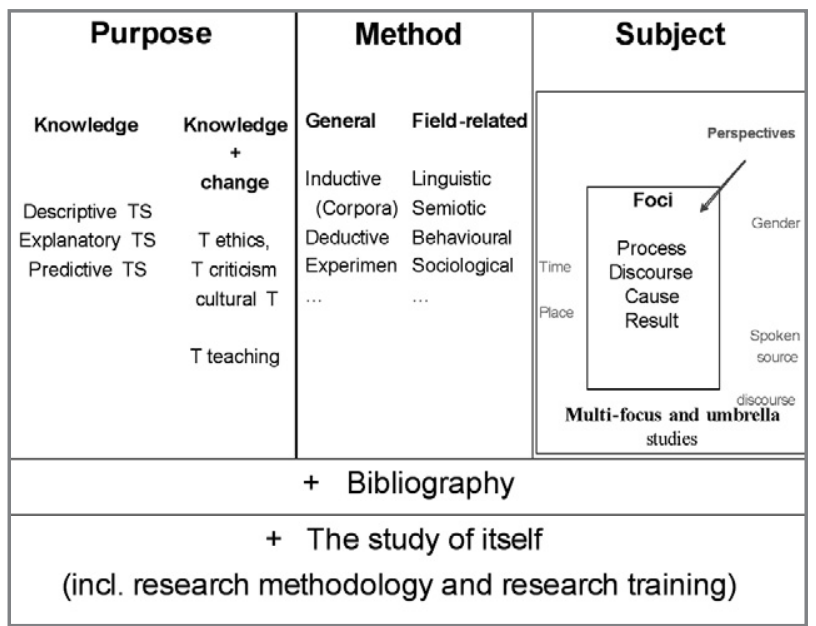

Using these classes, a universal thesaurus can now be built. In the appendix, the reader will find a translation studies thesaurus in which all the areas mentioned above are entered into their respective places. The thesaurus does not only incorporate all the various narrow terms of translation studies, but also a few related terms: in particular, some concepts that often appear in those fields, e.g., literal translation, directionality in translation studies, codes of practice, etc. are also included. As such, the thesaurus has the initial traits of an ontology $y^{13}$ under development.

The thesaurus is presented as a proposal, an invitation for discussion. Since it is a survey of a research field from a particular moment in time, it does not claim to be exhaustive, neither will it ever be final. As it is just the outset of a type of scholarly work surveying the ideas and models of every scholar involved in the field of translation studies, it is in need of refinement and completion through the cooperation of many.

\section{Advantages}

Like any other thesaurus, this one offers a clear, consistent and coherent system for the analysis of concepts and fields in translation studies. Not only will translation studies scholars benefit from this visually consistent presentation: its inherently didactic qualities will also promote translation studies among students.

Although the thesaurus is set up in English, its conceptually open structure allows inclusion of concepts from any culture. While translating the thesaurus into different languages will show up conceptual differences between languages, this does not mean that the thesaurus is culturally bound: on the contrary, all cultural differences are made visible and transparent, and in this way, it will contribute to knowledge sharing across cultures.

Apart from facilitating systematic indexing for bibliographic entries into a translation studies bibliography (whether the one published by Benjamins or the one by St. Jerome's), the thesaurus also has practical advantages: its map structure makes it possible to integrate all individual research activities of an institution into one 
system. The so-called research lines of a school can easily be made visible on a poster: the subject-based typology has proved suitable as a template that allows the Ghent School of Translation Studies to present its own research areas visually (Figure 9). Using the map as a template in this way will enable comparison of research activities in different translation schools worldwide. In the end, it will promote understanding, cooperation, and innovative research.

FIGURE 9

\section{Ghent School of Translation Studies Map (October 2003)}

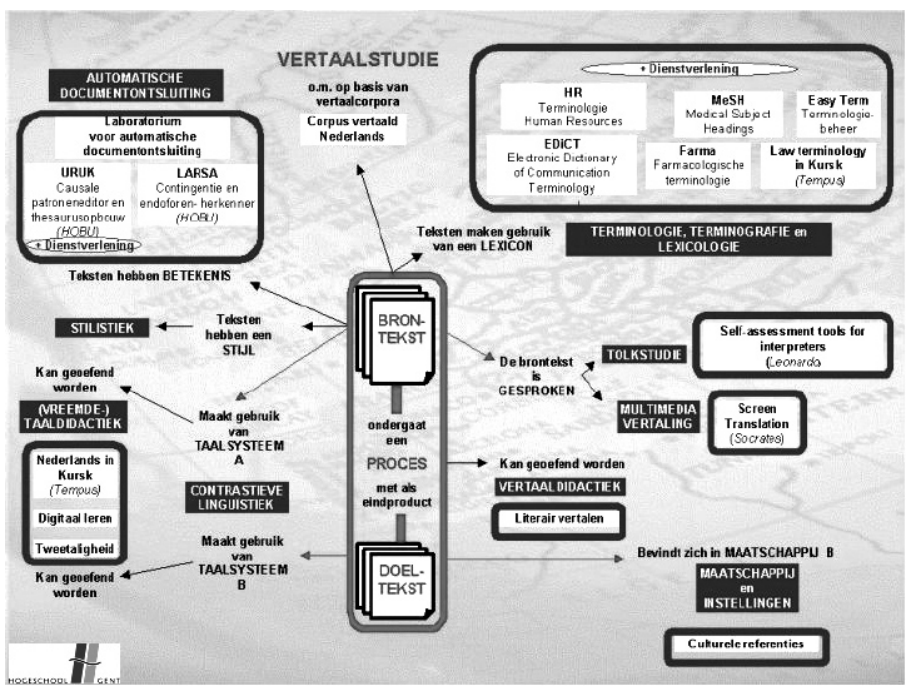

Is the exercise worthwhile? Any academic discipline broadens and deepens human understanding. In addition, translation studies is unique in that its object is just one human act, an act which crosses borders between languages and cultures, extremely complex as it may be and however different the forms it may take. What is special about this human act, about translation, is that it shares with academic disciplines the characteristic of broadening and deepening human understanding.

\section{NOTES}

1. The present text is a revised version of the paper presented at Doubts and Directions, $4^{\text {th }}$ Congress of the European Society for Translation Studies, Lisbon 2004. I would like to thank all colleagues for their comments, in particular F. Pöchhacker and R. Setton. I am also indebted to W. Vandeweghe for reading an earlier version.

2. The term 'state of affairs' is used in its broad philosophical sense to include all types of situations: actions, activities, events, processes and states (Wetzel 2003).

3. Theoretical studies are subdivided into 'General' and 'Partial,' and the latter are further subdivided into 6 subtypes.

4. To illustrate this type, an example of a study that is both descriptive and normative at the same time is Arnaud Laygues's 'Death of a Ghost: A Case Study of Ethics in Cross-Generation Relations between Translators' (St. Jerome Publishing's 2001), in which an ethical problem - a young translator having been exploited by one of her seniors - is explained by means of Marcel's concept of 
fidelity and Bourdieu's habitus (descriptive part) and in which solutions are suggested such as offering young translators more practical information during their initial training and providing better support from professional associations (normative part).

5. The multi-focus studies are different from Btranslation studies' 'multi-category works' (e.g., 2003), which are not restricted to different foci as research objects.

6. Note the interrelationship between some strategies and the purpose or result aimed at with the translation (see 5.4).

7. Other terms are: word-for-word translation and metaphrase (coined by Dryden 1680).

8. The hermeneutic motion (George Steiner 1975) sees translation as a hermeneutic act going through four stages: surrender to the source text, aggressive interpretation of it, assimilative incorporation and final restitution of its properties. The translator trusts "there is "something there" in the source text, something to be understood, something worth translating" (Chesterman 2000a: 180).

9. Toury (1977) sees the establishment of norms as the very epitome of a target-oriented approach: they determine the suitability of the role played by the translated text in a given cultural environment, so the translator must know them.

10. Williams and Chesterman refer to these studies as 'genre translation' (2002: 9ff).

11. The prescriptive approach in translation criticism can be easily justified in terms of describing a particular translation as the most relevant one or not relevant enough for a particular audience, in a particular place and at a particular time.

12. The former contains, amongst others, studies that focus on the metaphor of translation, such as gender metaphorics (Baker 1998a).

13. The term 'ontology' is used in the following sense: "a specification of a domain, of all that 'exists' in a domain, including terms, concepts, entities, axioms, theorems, laws, rules, and the actions than [sic] can be performed on everything within the domain as well as how to reason about the domain" (Krupansky 2004).

14. Sometimes, translatology is used in a narrower sense.

\section{REFERENCES}

Aitchison, J., Gilchrist, A. and D. Bawden (2000): Thesaurus Construction and Use: A Practical Manual, London, Aslib IMI.

BAKer, M. (ed.) (1998a): Routledge Encyclopedia of Translation Studies, London, Routledge.

BAKer, M. (1998b): “Translation studies," in BAKer, M. (ed.) Routledge Encyclopedia of Translation Studies, London, Routledge, pp. 277-280.

BAssnett, SusAn and A. Lefevere (eds.) (1990): Translation, History and Culture, London and New York, Pinter.

(1998-): Bibliography of Translation Studies, Manchester, St. Jerome.

Bush, P. (1998): "Pure language," in BAKer, M. (ed.), Routledge Encyclopedia of Translation Studies, London, Routledge, pp. 194-196.

CATford, J.C. (1965): A Linguistic Theory of Translation: An Essay in Applied Linguistics, London, Oxford University Press.

Chesterman, A. (2000a): Memes of Translation. The Spread of Ideas in Translation Theory, Amsterdam and Philadelphia, John Benjamins.

Chesterman, A. (2000b): "A Causal Model for Translation Studies," in Olohan, M. (ed.), Intercultural Faultlines. Research Models in Translation Studies I. Textual and Cognitive Aspects, Manchester, St. Jerome, pp. 15-27.

Delisle, J., Lee-Jahnke, H. and M. C. Cormier (1999): Terminologie de la traduction. Translation terminology. Terminología de la traducción. Terminologie der Übersetzung, Amsterdam and Philadelphia, John Benjamins.

Delisle, J., Lee-Jahnke, H. and M. C. Cormier (2003): Terminologie de la traduction. Translation terminology. Terminología de la traducción. Terminologie der Übersetzung, translated and adapted by Bloemen, H. and W. Segers, Terminologie van de vertaling, Nijmegen, Vantilt.

Essman, H. (1992): Übersetzungsanthologien: Eine Typologie und eine Untersuchung am Beispiel der amerikanischen Versdichtung in deutschsprachigen Anthologien, 1920-1960. (Neue Studien zur Anglistik und Amerikanistik 57), Frankfurt, Peter Lang. 
European Society for Translation Studies (2003): European Society for Translation Studies Directory 2003, Birmingham, Les, Aston University.

Gentzler, E. (1998): "Poetics of translation," in BAKer, M. (ed.), Routledge Encyclopedia of Translation Studies, London, Routledge, pp. 167- 170.

Gutr, E.-A. $\left(2000^{2}\right)$ : Translation and Relevance. Cognition and Context, Manchester, St. Jerome.

Hatim, B. (1998): "Pragmatics in translation," in BAKeR, M. (ed.), Routledge Encyclopedia of Translation Studies, London, Routledge, pp. 179-183.

Hermans, T. (1998): "Models of translation," in Baker, M. (ed.), Routledge Encyclopedia of Translation Studies, London, Routledge, pp. 154-157.

Holmes, J. (1972): The Name and Nature of Translation Studies, unpublished manuscript, Amsterdam, Translation Studies section, Department of General Studies, reprinted in Toury, G. (ed.) (1987): Translation Across Cultures, New Delhi, Bahri Publications.

Holmes, J. (1988): Translated! Amsterdam, Rodopi.

Jakobson, R. (1959): "On Linguistic Aspects of Translation," in Brower, R. A. (ed.), On Translation, Cambridge, Harvard University Press, pp. 232-239.

KRUPANSKY, J. (2004): “Definition: ontology," <http://agtivity.com/ontology.htm>, [07.11.2004].

Lederer, M. (1980): La traduction simultanée. Fondements théoriques, Lille, Université de Lille III.

Lederer, M. (1981): La traduction simultanée. Expérience et théorie, Paris, Minard.

Levý, J. (1967): “Translation as a Decision Making Process," in To Honor Roman Jakobson, vol. 2. The Hague, Mouton, pp. 1171-1182.

Olohan, M. (1998): The Role of Theory in Enhancing the Explanatory and Predictive Aspects of Translation Process Research, Ph.D. thesis, UMIST.

Olohan, M. (2004): Introducing Corpora in Translation Studies, London and New York, Routledge.

Рyм, A. (ed.). (2001): “The Return to Ethics," The Translator 7-2, St. Jerome Publishing, <http:// www.stjerome.co.uk/translator/vol7.2.htm\#laygues>, [14.09.04].

Рум, A. (2002): "Redefining translation competence in an electronic age. In defence of a minimalist approach," <http://www.fut.es/ apym/on-line/competence.pdf>, [26.10.2003].

Schäffner, C. and B. AdAB (eds.) (2000): Developing Translation Competence. Benjamins Translation Library 38, Amsterdam and Philadelphia, John Benjamins.

Simon, S. (1996): Gender in Translation: Cultural Identity and the Politics of Transmission, Translation Studies, London, Routledge.

Steiner, G. $\left(1975,1992^{2}, 1998^{3}\right)$ : After Babel, Oxford, Oxford University Press.

Toury, G. (1977): Translational Norms and Literary Translation into Hebrew, 1930-1945. Tel Aviv, The Porter Institute for Poetics and Semiotics, Tel Aviv University.

Toury, G. (1995): Descriptive Translation Studies and Beyond, Benjamins Translation Library 4, Amsterdam and Philadelphia, John Benjamins.

Uwajeh, M. K. C. (2002): "The Task of the Translator Revisited in Performative Translatology," Babel 47-3, pp. 228-247.

Venuti, L. (1995): The Translator's Invisibility, London and New York, Routledge.

Venuti, L. (ed.) $\left(2000,2004^{2}\right)$ : The Translation Studies Reader, London and New York, Routledge.

von Flotow, L. (1997): Translation and Gender. Translating in the "Era of feminism," Manchester, St. Jerome Publishing.

Wetzel, T. (2003): "States of Affairs," in Zalta, E. N. (ed.), The Stanford Encyclopedia of Philosophy (Fall 2003 Edition), <http://plato.stanford.edu/archives/fall2003/entries/states-ofaffairs/>, [07.11.2004].

Williams, J. and A. Chesterman (2002): The Map. A Beginner's Guide to Doing Research in Translation Studies, Manchester, St. Jerome Publishing. 
584 MetA, LIII, 3, 2008

\section{APPENDIX}

LT $=$ Lead Term
BT $=$ Broad Term
NT $=$ Narrow Term
RT $=$ Related Term
UF $=$ used for (a synonym with a lower frequency)

translation studies

UF translatolog $\mathrm{y}^{14}$

BT: intercultural communication studies

BT: multi-lingual communication studies

-NT: translation studies bibliography

-NT: studies of translation studies research methodology

NT: studies of the metaphor of translation

RT: gender metaphorics

-NT: studies of translation studies research training

-Types by purpose

NT: Translation theory

UF: 'pure translation studies'

UF: translatology

UF: models of translation

NT: descriptive translation studies

NT: explanatory translation studies

NT: predictive translation studies

NT: Normative studies

UF: 'Applied translation studies'

NT: translation teaching models

NT: translation ethics

NT: cultural translation

-Types by method

Types by general research methods

NT: inductive translation studies

NT: corpus(-based) translation studies

NT: qualitative approaches

NT: quantitative approaches

NT: hermeneutic approaches

NT: deductive translation studies

NT: experimental translation studies

RT: think-aloud protocol studies UF: TAP studies

NT: speculative approaches

Types by field-related research methods

NT: linguistic approaches

NT: neurolinguistic approaches

NT: psycholinguistic / Cognitive approaches

NT: behavioural translation studies

NT: communicative / Functional approaches

NT: semiotic approaches

NT: sociological approaches

-Types by subject

NT: single-focus translation studies

NT: process-oriented translation studies (incl. cognitive processes)

NT: studies of translation competence

NT: translation commentaries focussing on the process

NT: studies of decision making in translation 
NT: studies of translation strategies

RT: adaptation

RT: domestication

RT: equivalence

RT: explicitation

RT: foreignization

$\mathrm{RT}$ : free translation

RT: imitation

RT: literal translation

UF: word-for-word translation UF: metaphrase

RT: paraphrase

RT: sense-for-sense translation

NT: studies of linguistic translation techniques

NT: compensation

$\mathrm{RT}$ : shifts of translation

NT: studies of translation and technology

NT: machine translation studies

NT: machine(-aided) translation studies

NT: studies of evaluating software

NT: software localization studies

NT: studies of effects of technology

NT: website translation studies

RT: directionality in translation

RT: translatability

RT: unit of translation

RT: game theory

RT: pure language

NT: studies of translation teaching

UF: studies of translation training

UF: studies of translation didactics

RT: language teaching studies

RT: curriculum design

RT: curriculum implementation

RT: translation assessment

UF: translation evaluation

RT: translator-training institutions

RT: place of technology in translator training

NT: translation profession studies

NT: workplace studies

RT: professional development

RT: codes of practice

RT: translators' organizations

NT: AIIC

NT: FIT

RT: translation quality

UF: translation quality assessment

NT: discourse-oriented translation studies

NT: comparative discourse-oriented translation studies

NT: source-oriented translation quality assessment studies

RT: multilingualism in translation

NT: target-oriented translation quality assessment studies

RT: comparable texts

$\mathrm{RT}$ : translation universals 
RT: contrastive linguistics

RT: contrastive pragmalinguistics

RT: contrastive pragmatics

RT: contrastive discourse analysis

RT: comparative linguistics

RT: contrastive area studies

RT: analytical philosophy

NT: non-comparative discourse-oriented translation studies

RT: anthologies of translation

RT: script in translation

RT: applied linguistics

RT: textology

RT: linguistics

NT: Semantics

NT: syntax

NT: phonology

RT: text linguistics

UF: textology

RT: sociolinguistics

RT: critical linguistics

RT: stylistics

RT: discourse studies

RT: dialogue language

RT: critical discourse analysis

RT: technical writing

RT: translation of humour

RT: translation of wordplay

RT: translation of metaphor

RT: lexicography

RT: lexicology

RT: terminology

RT: term banks

RT: glossaries

RT: terminography

RT: terminotics

RT: thesaurus building

RT: ontology building

RT: semiotics

RT: automatic content retrieval

NT: Cause-oriented translation studies

RT: publishing strategies

RT: translation politics

RT: ethnocentric violence of translation

RT: the cultural turn in translation studies

NT: Result-oriented translation studies

NT: effect-oriented translation quality assessment studies

RT: action theory

RT: skopos theory

RT: theory of translatorial action

RT: polysystem theory

RT: the translator's invisibility

RT: translation and cultural identity

RT: translation and ethics 
NT: Multi-focus translation studies

NT: Umbrella translation studies

NT: Interpreting studies

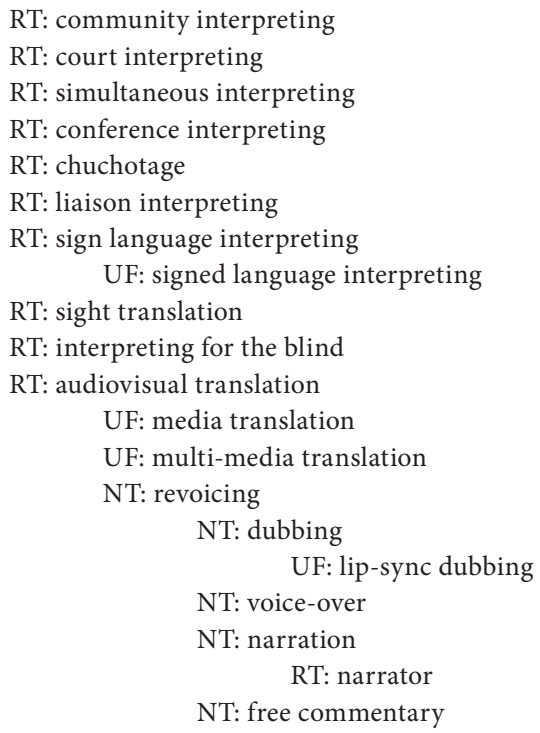

NT: subtitling

NT: surtitling

NT: Register translation studies

RT: religious translation

NT: Bible translation

NT: Koran translation

NT: Torah translation

RT: translation of political texts

RT: translation and politics

RT: LSP translation

UF: specialized translation

NT: academic translation

UF: scientific translation

NT: translation of tourism texts

NT: translation of business communication

UF: economic translation

NT: translation of advertising

RT: business communication studies

NT: legal translation

NT: court interpreting

NT: technical translation

RT: literary translation

UF: translation and literature

NT: genre translation

NT: drama translation

NT: theatre translation

NT: opera translation

NT: poetry translation

NT: prose translation

UF: fiction translation 
NT: Shakespeare translation

RT: children's literature and translation

RT: literary studies

RT: comparative literature studies

NT: translation ciriticism

RT: auto-translation

RT: translation and gender

RT: feminist translation

RT: history of translation

RT: intertemporal translation

RT: ideology and translation

RT: socio-political aspects of translation

RT: pragmatics of translation

Examples of multi-focus subject studies

Discourse and process

RT: hermeneutic motion

$\mathrm{RT}$ : direction of translation

RT: translation commentaries relating the target text to the process Discourse and result

$\mathrm{RT}$ : translation reviewing and criticism

RT: quality assessment

UF: translation evaluation

Cause and result

RT: translation ethics

RT: personal vs. professional ethics

RT: norms

RT: image of the Other

RT: untranslatability

RT: cultural and intercultural studies

RT: postcolonialism

RT: postmodern theories

RT: translation and cultural identity

Cause, discourse and result

RT: poetics of translation

Process, discourse and result

RT: localization 